\section{A LEVEL PLAYING FIELD}

I guess the 'brochure' never claimed that (much as we want it to be wrong) the world is balanced and equitable. As the selections illustrate, it is, though, what we should continue to aspire to - being on the same field is a reasonable place to start.

\section{COSTS OF ILLNESS: CHILD PNEUMONIA IN LOW AND MIDDLE INCOME COUNTRIES}

Let's start with some positives: in 2000, global child deaths from pneumonia numbered around 1.7 million, but, by 2017 had dropped (by GBD estimates) to 809000 . The introduction of haemophilus $B$ and penumococal vaccination to routine surveillance has been a big factor as have enhanced recognition (through the Integrated Management of Childhood Illness approaches) and improved pre-, peri- and postnatal care of children whose mothers have HIV. There is though, an elephant in this particular room. The costs of care for many families, both direct medical and non-medical (accomodation, for example) and indirect in the form of loss of productivity and salary is daunting. In an estimated costs of illness study,

Department of Women's and Children's Health, International Maternal and Child Health (IMCH), Uppsala University, Uppsala, Sweden; Department of Paediatrics, Länssjukhuset Gävle-Sandviken, Gävle, Sweden; Department of Child Health, Aga Khan University, Karachi, Pakistan

Correspondence to Dr Nick Brown, Department of Women's and Children's Health, International Maternal and Child Health (IMCH), Uppsala University, Uppsala, Sweden; nickjwbrown@gmail.com
Marufa Sultana and colleagues from the ICDDB-R assessed the household financial impact of a hospital admission for a child with pneumonia. The results provide a pretty clearcut pointer for intervention with an admission costing a poor urban family the equivalent of $43 \%$ of a monthly income and, for their rural counterparts, $20 \%$. Add to this that approximately $80 \%$ of global pneumonia mortality is out of hospital so any means of encouraging families to seek help early but ensure this is economically feasible is to be welcomed. Health insurance seems to be the key. See page 539

\section{CHOLESTEROL}

Conceptually, screening is quite straightforward. For a programme to 'work', the prerequisites are as follows: a common problem; a sensitive test with a high positive predictive value; feasibility; acceptability and an effective treatment. Cardiovascular disease stubbornly remains at the top table for mortality and the origins are acknowledged to be early in life. Familial hypercholesterolaemia is a major contributor to coronary heart disease: there is a simple sensitive and specific screening test and, once identified is treatable with statins at an appopriate age currently 8 years. There's another bonus too, if children are identified, their parents (who will be at high risk) can also be screened and, if also positive, saved, by starting statin treatment rather than dying prematurely. The earlier treatment starts, the better the chance for the parent and, later on once statins can be started, the child. Combining the screen with the 1 year vaccinations, would spare both appointments and distress. David Wald and Andrew Martin argue the case 'for'. See page 525

\section{A point in history}

In a poignant Voices from history, reflection, Samuel Schotland describes the inspiration for and development of the seminal Bridge programme for street youths and homeless in Boston at the start of the 1970s inaugurated by Andrew Guthrie an adolescent physician. Though one could argue the case for turmoil in many eras, before and after, but the then epidemic levels of homelessness, homophobia, drug addiction that had been fermenting during the 1960s makes this period stand out. The idea was a simple one: to provide support, medical, psychological and social help to the hordes of children who had found themselves in hard times. The vehicle (literally and metaphorically) was a van which doubled as clinic, social work centre and rehabilition co-ordinator. Fast forward 50 years, multiple iterations (700 in the US alone) and numerous lives changed, it's hard to overstate the influence of the project or the way in which it personified a decade which began with the US withdrawal from Vietnam and ended with the USSR wresting for control over Afghanistan. See page 615

Have we gone forwards or backwards?

ORCID iD

Nick Brown http://orcid.org/0000-0003-1789-0436 